\title{
Postrape care services to minors in Kenya: are the services healing or hurting survivors?
}

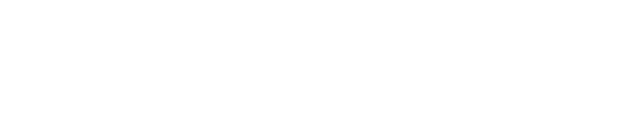

\author{
Cynthia Khamala \\ Wangamati' \\ Viva Combs Thorsen' \\ Abdi Ali Gele ${ }^{2}$ \\ Johanne Sundby' \\ 'Department of Community Medicine, \\ Faculty of Medicine, University \\ of Oslo, ${ }^{2}$ Department of Nursing \\ and Health Promotion, Faculty of \\ Health Sciences, Oslo and Akershus \\ University College of Applied \\ Sciences, Oslo, Norway
}

\begin{abstract}
Child sexual abuse is a global problem and a growing concern in Sub-Saharan Africa. It constitutes a profound violation of human rights. To address this problem, Kenya has established the Sexual Offences Act. In addition, Kenya has developed national guidelines on the management of sexual violence to grant minors access to health care. However, little is known about the experiences of sexually abused minors when they interact with the health and legal system. Accordingly, this study uses a triangulation of methods in the follow-up of two adolescent girls. Health records were reviewed, interactions between the girls and service providers were observed, in-depth interviews were conducted with the girls, and informal discussions were held with guardians and service providers. Findings indicated that the minors' rights to quality health care and protection were being violated. Protocols on postrape care delivery were unavailable. Furthermore, the health facility was ill equipped and poorly stocked. Health providers showed little regard for informed assent, confidentiality, and privacy while offering postrape care. Similarly, in the justice system, processing was met with delays and unresponsive law enforcement. Health providers and police officers are in grave need of training in sexual and gender-based violence, its consequences, comprehensive postrape care, and sexual and reproductive health rights to ensure the protection of minors' rights. Health administrators should ensure that facilities are equipped with skilled health providers, medical supplies, and equipment. Additionally, policies on the protection and care of sexually abused minors in Kenya require amendment.
\end{abstract}

Keywords: child sexual abuse, postrape care, rights, guidelines, sexual violence

\section{Introduction}

Sexual violence against minors is a grave violation of human rights and a major public health concern. Recent meta-analyses of child sexual abuse reported a global prevalence of $18 \%-20 \%$ for girls and $8 \%$ for boys. ${ }^{1,2}$ Extant literature in Africa indicates that $5 \%-15 \%$ of females experience coerced coitus. ${ }^{3}$ A large study conducted among 13- to 15-year-old school children in Namibia, Swaziland, Uganda, Zambia, and Zimbabwe reported an average of $23 \%$ lifetime exposure to sexual violence. ${ }^{4}$ According to a Kenyan Violence Against Children 2010 national survey, $7 \%$ of females aged 18-24 experienced forced sexual intercourse prior to 18 years of age. ${ }^{5}$ Twelve months prior to the survey, $\sim 11 \%$ of girls and $4 \%$ of boys aged $13-17$ years had experienced some type of sexual violence. ${ }^{5}$

Physical ramifications of sexual violence include traumatic injury, sexually transmitted illnesses, unwanted pregnancies, unsafe abortions where abortion is legally restricted, and complications during pregnancy, including obstetric fistulas. ${ }^{6}$ Psychological consequences may include clinical depression, posttraumatic stress disorder, conduct disorders, alcohol and illicit drug abuse, and suicide attempts. ${ }^{7,8}$
Correspondence: Cynthia Khamala Wangamati

Department of Community Medicine, Faculty of Medicine, University of Oslo, PO Box II30, Blindern, 0318 Oslo, Norway

Tel +254 7II 824504

Email cynthia.wangamati@medisin.uio.no
International Journal of Women's Health 2016:8 249-259

(c) (1) (8) (2016 Wangamati et al. This work is published and licensed by Dove Medical Press Limited. The full terms of this license are available at https:/www.dovepress.com/terms.php cc. hereby accept the Terms. Non-commercial uses of the work are permitted without any further permission from Dove Medical Press Limited, provided the work is properly attributed. For permision for commercial use of this work, please see paragraphs 4.2 and 5 of our Terms (https://www.doveppess. com/terms.php). 
There is an increased risk of revictimization and confused traumatic sexuality in adulthood among children who have experienced sexual abuse. ${ }^{9}$

Since survivors of sexual violence often experience a deep sense of powerlessness, it is imperative that postrape care services aim at empowering them. ${ }^{10}$ Timely, objective, ethical, and nonjudgmental care and continuity of care are essential for power reclamation. ${ }^{10,11}$ The World Health Organization recommends that postrape care services be offered with a focus on rights of minors rather than needs. ${ }^{12}$ The aforementioned approach integrates norms, standards, and principles of international human rights' agreements into national laws, policies, and plans, which in turn promote quality health care. ${ }^{13}$

Laws, policies, and international conventions grant everybody, including minors, the right to the highest attainable standard of health. ${ }^{12,14}$ Quality health care is guaranteed through a functional health care system equipped with quality medical supplies, equipment, and sufficient skilled health providers. ${ }^{12}$ Signatories of the convention on the rights of the child have the obligation to ensure that quality postrape care services are available, accessible, and affordable. ${ }^{12}$ Moreover, the services should be timely while fostering informed consent and decision making, respect, dignity, bodily integrity, privacy, and confidentiality. ${ }^{12,15}$ However, studies have noted that sexual and reproductive health services granting minors' rights to privacy and confidentiality are limited, and the laws that are intended to protect minors from sexual violence are poorly enforced..$^{16,17}$

As a signatory of the convention on the rights of the child, Kenya has developed laws and policies to protect survivors of sexual violence from abuse and their sexual and reproductive health rights. National guidelines on the management of sexual violence have been established to guide the provision of comprehensive postrape care. Care entails history taking, physical examination, collection and preservation of forensic evidence, screening and treatment of sexually transmitted infections (STIs), including HIV, pregnancy testing for eligible girls, and relevant vaccinations (tetanus and hepatitis B). Trauma counseling and pyschoeducation, counseling related to the possibilities of pregnancy, and STIs are considered as the components of postrape care. The Ministry of Medical Services and the Ministry of Public Health and Sanitation recommend that the guidelines be available in all health facilities. Although the availability of the national guidelines in health facilities is unknown, reports point to weak implementation of the guidelines. ${ }^{17}$

The guidelines emphasize the need for informed assent and consent from the child and the guardian, respectively, by explaining all aspects of the consultation. ${ }^{18}$ It is clear that an examination should never be forced and examining a patient without consent could result in charges of assault and breach of privacy. ${ }^{18}$ However, issues regarding confidentiality and privacy are not sufficiently addressed within the guidelines. Health providers are advised to ensure privacy with no instructions on how to do this. In efforts to maintain confidentiality, the guidelines recommend that adolescents be interviewed in the absence of their parents. ${ }^{18}$ However, how to keep the information shared by minors confidential in such situations is not addressed. Although health providers are advised to inform the survivors that the shared information may be disclosed to authorities for legal reasons, ${ }^{18}$ no emphasis is given to assure minors that confidentiality will be upheld by third parties who receive the shared information. Studies show that the inability to guarantee confidentiality for adolescents seeking sexual and reproductive health care is likely to reduce the number of young people seeking such care and may adversely affect the physician-patient communication, as well as the continuity of care. ${ }^{19-21}$

Minors have a right to be protected from all kinds of sexual abuse. ${ }^{22}$ The Government of Kenya enacted the Sexual Offences Act in 2006 that outlines penalties for child sexual abuse, including imprisonment and fines but no legal redress for complainants. ${ }^{23}$ The objective of sexual violence legislation is for the protection of fundamental rights of individuals through punishing and prosecuting perpetrators so as to deter perpetrators and provide justice. ${ }^{24}$ Although the Sexual Offences Act enactment is an indicator of progress, its implementation has been reported to be slow. ${ }^{24}$ This is partly due to the low levels of awareness of the Act and its provisions by implementers in government agencies and departments, the police, prosecution, the judiciary, and the general public. ${ }^{24}$

The rights of survivors of sexual violence are poorly understood by many actors due to difficulties in their operationalization in relevant programs..$^{25,26}$ Little is known about the experiences of sexually abused minors as they interact with the health and the legal system. Furthermore, no research has been conducted in Kenya to document sexual and reproductive rights' observations and violations for minors seeking postrape care services. Therefore, the aim of this article is to highlight sexual and reproductive health rights' observations and violations experienced by minors seeking postrape care services.

\section{Methods}

This article is based on two cases drawn from a qualitative study that assessed the quality of postrape care given to sexually abused minors at a district health facility located in 
Homa Bay County within Western Kenya. The study took place from January 2013 to June 2014. Data collection methods were triangulated in order to gain a more comprehensive picture of the dynamic processes and pathways a minor faces while interacting with the health and legal system. The methods included review of available health records, observations, in-depth interviews with the cases, and informal conversations with service providers and guardians.

For the larger study, snowball sampling was used to recruit the cases. These cases were referred to the first author by health providers when the cases sought postrape care at the health facility. Both the cases described herein were school-aged minors living with their grandparents in the outskirts of Homa Bay town. In-depth interviews were held with cases to find out the type of health care and legal services that they received. With the help of a certified government clinician, available health records of the respective cases were reviewed to find out the forms of treatment provided to minors. Observations were done to gather information on client-service provider interaction, average client waiting times, and client movement from entry into, to exit from, the health care. Informal discussions were then held with guardians, health providers, and police officers to shed light on the circumstances surrounding the incident and health and legal services that were provided or not. Field notes were taken to supplement the observations and informal discussions.

The participating health facility was a teaching and referral center that offered preventive, curative, and rehabilitation services. Within the health facility, postrape care services are said to be available 24 hours a day, 7 days a week with responsibility allocated to the outpatient department (OPD) and patient support center (PSC). The PSC was run by an international nongovernmental organization (INGO) in collaboration with the Kenyan Ministry of Medical Services and offered health services and support to people living with HIV/AIDS. The INGO operates only on week days between 8 am and $5 \mathrm{pm}$. The mechanism through which sexually abused minors are processed at the health facility and police station is depicted in Figure 1. In general, sexually abused minors primarily come from the nearby police station (10 minutes walk away). They were first seen at the OPD, in a room reserved for the forensic examination (Figure 1). During the examination, health providers are mandated to document findings in the following two structured standard forms: 1) a PRC1 form, which is a document that allows for history taking, documentation, and examination of a survivor of sexual assault and 2) a P3 form, which is issued at the police station to be filled in by a health practitioner or by the police surgeon as evidence that an assault has occurred. ${ }^{18}$
After the examination, survivors are referred to the PSC for counseling and clinical care. When done, they are referred back to the police station with filled in PRC1 and P3 forms. Because there are no other organizations providing such services in the area, survivors seeking assistance out of the working hours (after $5 \mathrm{pm}$ or on the weekends) are forced to return back when the PSC is open. This delays the clinical and psychosocial support they need and potentially leads to cases falling out. Figure 1 elaborates on the movement of patients within the health facility and police station.

The analytical process began in the field during data collection. As the gathered data were analyzed, it shaped the ongoing data collection process. The interviews, conducted in Swahili, were recorded and transcribed verbatim. In addition, notes obtained from observations and informal discussions were reviewed by the first author for the purpose of contextualizing the process being investigated. Later, the first author read and reread the transcripts and field notes to familiarize and understand the data in order to derive meaning. The data were then coded manually by the first author, and the codes were counter checked by the second, third, and fourth authors.

This study was carried out in accordance with the Declaration of Helsinki. It was approved by the Norwegian Regional Committee for Medical and Health Research Ethics in Norway, and the Kenyatta University Ethics Review Committee in Kenya. To carry out the study within the health facility, written informed consent was obtained from the Medical Superintendent. Within the police station, verbal consent was obtained from the county police commandant. For observation of and interviews with the cases, assent was obtained from the girls, and verbal and written consent was obtained from the girls' guardians, the police officers, and the health providers providing postrape care services to the girls. As for the review of health records, written consent was obtained from the medical superintendent, and verbal consent was obtained from guardians.

\section{Results \\ Edna}

"Edna" was a 14-year-old minor enrolled at a local government-funded primary school. She came from a family of eight members and lived in the outskirts of the Homa Bay town. She lived with her maternal grandfather and grandmother who were small-scale farmers. Edna's mother did not have a stable partner and therefore moved around a lot. The whereabouts of Edna's father were unknown.

Edna, the police officer, and Edna's friend (seated at the OPD) were introduced to the research team. The research team then shared the research objectives with them and 


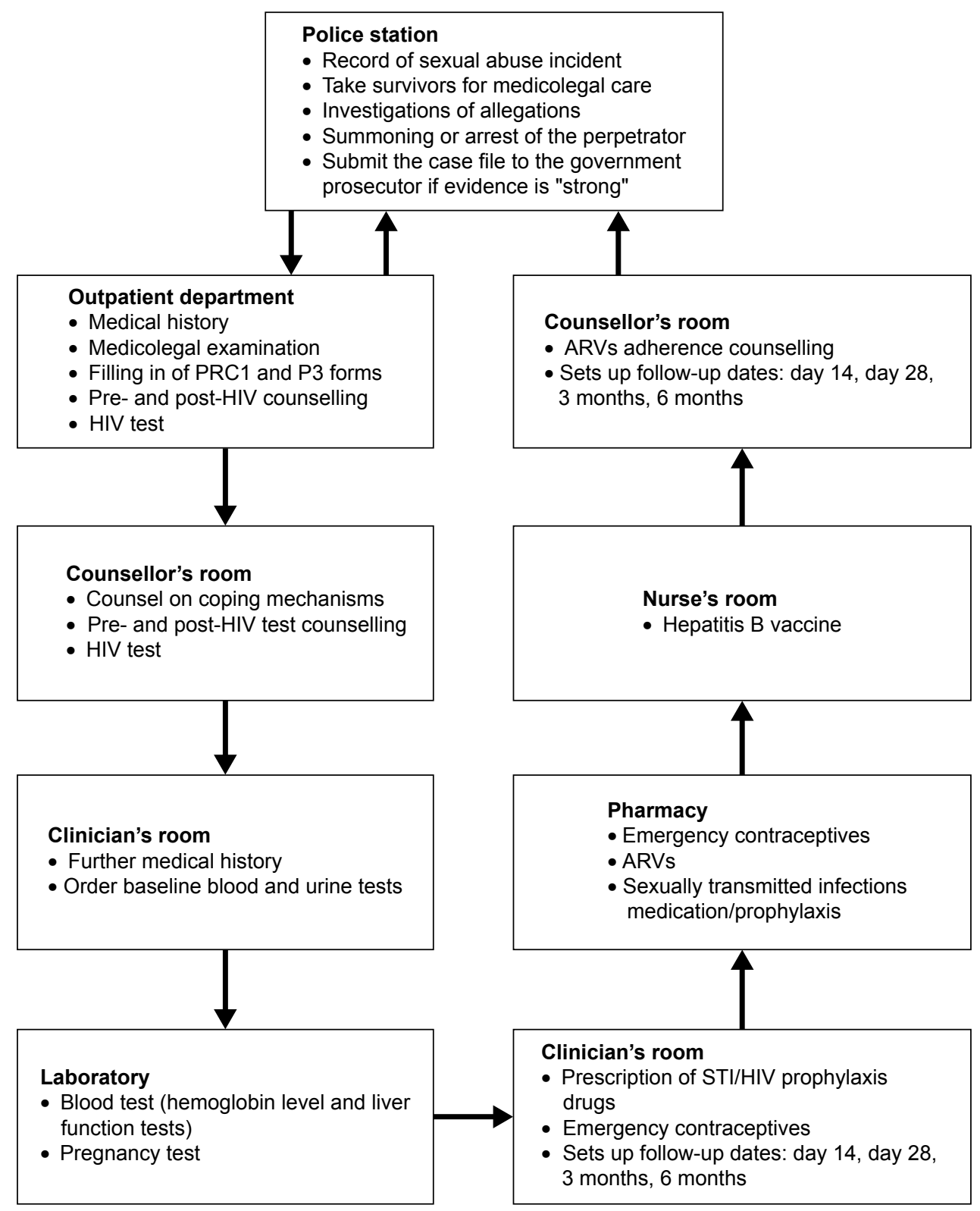

Figure I Movement of survivors between the health and legal system.

Abbreviations: ARVs, antiretrovirals; HIV, human immunodeficiency virus.

also explained that the study entailed observation of the treatment process and gave details on the possible aspects of the physical and forensic examination. These aspects had the possibility of causing embarrassment to Edna and therefore she was told that she had the right to withdraw from the study anytime if she felt uncomfortable without any consequences. The research team also assured her that her withdrawal would not affect the quality of treatment in anyway. Privacy and confidentiality of the shared information were assured. The research team also explained that her participation in the research would contribute to knowledge on the quality of postrape care service provision, and if services were not up to the required standard, the information will be useful to help improve postrape care services within the health facility. All were given the opportunity to ask questions and state their concerns. Later, verbal consent was sought from the police officer and assent was sought from Edna for recruitment purposes. Consent was sought from the police officer because at the time she was acting as Edna's guardian. The police officer was a friend of Edna's family friend who had called in a favor, requesting her to take Edna to the police station to report the incident. At the time, the female police officer was off duty. On reaching the police station to file the report, she found that the female police officer in charge of 
sexual abuse cases was on short leave, and therefore she was requested to take Edna to the health facility for medical examination. In addition, the research team asked Edna for her guardian's phone number, shared the study's objectives with her, eg, what the study entailed, and explained that the minor's participation was voluntary and lack of consent had no implications on the quality of care received. The research team also assured her of privacy and confidentiality of the shared information. She consented to the study. The research team also considered that their presence in the room may intimidate Edna; this concern was shared by the nurse who offered not to observe the treatment but would be in the room just in case the medical officer needed assistance. Edna was informed of the arrangement and was asked if it would intimidate her or frighten her, but she said that she was fine with the arrangement.

\section{Edna's interaction with health providers}

At that point of the meeting, Edna had been tested for HIV by the nurse and was given a start dose of antiretroviral drugs, which were to last for 3 days. The standard procedure was the administration of postexposure prophylaxis drugs for 14 days after which the survivor would return for the other half dose on day 14 . Usually, the prophylaxis was administered by the INGO, but Edna arrived on a weekend evening, which was out of the operating hours of weekdays between 8 am and $5 \mathrm{pm}$. Therefore, she was asked to come back on Monday for an additional dose of antiretrovirals. Additionally, she was given a prescription for emergency contraceptives because they were out of stock.

The first author, the research assistant, Edna, and police officer waited for the examining medical officer for approximately one and a half hours. During the waiting period, inquiries about the day's events were made. Edna reported that she had been abused in the previous night and reported the incident to the main police station in the afternoon whereby she was requested to record a statement detailing the assault. Thereafter, a standard P3 form that was to be filled in by a health practitioner as evidence that an assault had occurred was issued and she was told to proceed to the health facility. The first author asked the nurse about the whereabouts of the medical officer. She was informed that the medical officer was performing ward rounds and would be there shortly.

The medical officer finally came in and asked loudly for the girl who had been raped. Edna stood up and followed him to the examination room. We followed suit and introduced ourselves. After the introduction, he asked Edna about her ordeal. Edna narrated that she had woken around $11 \mathrm{pm}$ to relieve herself outside. As she came back from the latrine, a man who happened to be a close neighbor intercepted and dragged her toward a nearby maize plantation. She resisted and tried to scream. The man responded by slapping her hard and threatened to kill her if she tried to scream. He then dragged her into the maize plantation and raped her.

The medical officer asked her if she had changed her clothing and taken a bath. Her response was negative. He also asked her to stand up and turn around. He then asked her to undress behind a curtain that separated the room and lie on the bed so that he could examine her. During the examination, the medical officer realized that he did not have gloves and went out of the room to look for a nurse to give him gloves. The nurse's response was that the gloves were out of stock. She asked Edna if she had money to buy the gloves. Edna told her that she had no money. The nurse decided to go out and ask her colleagues for extra gloves. In that event, we offered to buy the gloves as the girl lay naked on the examination bed for $\sim 5-10$ minutes waiting for the nurse.

With the gloves on, the medical officer proceeded to perform a physical examination. Then, he instructed Edna to put her legs in a frog leg position for a genital examination. Realizing he had no lubricant, the medical officer rushed out to get it. In the meantime, Edna felt shy and covered her face as she was naked. The medical officer came back and proceeded with the examination. The officer seemed to have trouble seeing due as the fluorescent light on the ceiling was not working. He asked if any of us had a torch (aka flash light), which we did not. Fortunately, his phone had a small torch that was held by the research assistant to enable the medical officer to conduct the examination. The medical officer concluded that there were no lacerations, but the research assistant (a certified clinical officer) pointed out that the girl's inner thigh had lacerations. He noted them and concluded the examination.

The medical officer filled in the standard PRC1 form, which is a document that allows for history taking, documentation, and examination of a survivor of sexual assault and P3 form. He then handed the completed forms without making copies to the police officer who left with Edna. Having noticed that the medical officer had used an adult speculum to conduct the speculum examination and failed to collect any samples, the first author inquired on reasons for the practice. He stated that the facility had only one speculum for children, which was unsterilized, and that collecting specimens was not his job. According to him, the responsibility of collecting samples lay with the laboratory technician. 
Later, inquiries with regard to the collection of samples from survivors of rape were made from the medical officer in charge of the obstetrics and gynecology ward. He reported that it was the duty of the examining medical officer to collect samples from survivors. The examining medical officer was new (having completed medical school a few weeks previously) and therefore lacked experience in conducting medicolegal examination. We also made inquiries on protocols regarding postrape care. Protocols as well as rape kits were unavailable in the health facility.

\section{Edna's interaction with the legal system}

The following day (after Edna's examination), the first author and the research assistant went to meet Edna's family for an interview. Upon arrival, they were informed by Edna's grandfather that she was recording another statement at the local police station, which was a sub-branch of main police station. We accompanied him to the station where assent from Edna and verbal and written consent from Edna's guardians were obtained. The grandfather informed us that they had been at the police station since morning (we arrived there at $1 \mathrm{pm})$. After half an hour, the policeman in charge of Edna's case informed us that she had to accompany them to the crime scene. We proceeded to the crime scene, which was near Edna's home. The perpetrator had fled upon knowledge that an arrest would be made.

The following Monday, Edna went back to the main police station and recorded another statement. The activity took long such that by the time Edna made it to the facility, INGO clinic clinicians had left for the day. However, she met the counselor who counseled her on adherence to antiretroviral drugs. The counselor requested the pharmacist to give her medication for 1 day, and Edna was advised to return the next day.

After seeing the counselor, the research assistant asked Edna what happened at the police station. She said:

They just kept us waiting and waiting from morning. (How did that make you feel?) Tired. (Then what happened?) The policeman from yesterday then asked me to tell him what that man did to me again and if I had seen that man (alleged perpetrator). (Did he come back?) No, he is still hiding.

Edna then left but failed to turn up the next day. Worried that Edna's failure to continue with the medication would put her at a risk for HIV, her grandmother was phoned several times and requested to urge Edna to return for an additional dosage. She did not turn up prompting us to phone her grandmother again to find out reasons for her reluctance. Her response was that Edna had gone missing.
A few days later, the research team was informed by the police officer handling Edna's case that he thought the issue would be resolved at home. According to the information he had obtained, a group of people were sent by the perpetrator to Edna's grandfather to negotiate an agreement to arbitration. Apparently, payment of fines by the perpetrator to the survivor's family was a common method of resolving rape cases. Three weeks later, the research team managed to meet Edna's grandfather who informed them that Edna was still missing. Despite her disappearance, he had not filed a missing person report to the police. By the end of the study, Edna had not returned to her grandparents.

\section{Christine}

"Christine" was a 14-year-old girl. She attended a local primary school in the outskirts of Homa Bay town. She was the second child from a family of eight members. The whole family resided with the grandmother as her mother had died in the year 2000. Upon her death, their father abandoned them forcing the maternal grandmother to take them in. Her grandmother was a traditional birth attendant who owned a small grocery shop at the nearby local market.

The research team met Christine on her second visit to the PSC. She was introduced to the researchers by the counselor. She had come in for a second dose of antiretroviral drugs and adherence counseling. Christine had walked for an hour to make the appointment. Since she was unaccompanied, the research team did not interview her. Instead, she was asked for her guardian's phone number, who was phoned and requested for a meeting the next day.

The following day, the research team traveled to Christine's home. They introduced themselves and sought assent and consent from Christine and her guardian, respectively. Later, they requested to interview Christine privately.

They proceeded to ask her about the ordeal. She narrated:

The way I told them (medical staff), that boy (the alleged perpetrator-15 years old) normally comes here to study with those boys who are outside (referring to her brothers who were outside the house). So that day .... We normally study together. So that day I felt sleepy and went to sleep on that bed (points at a bed in the living room). My sister wasn't there. So I told those boys when they leave to wake me up to close the door. Its like ... when I went to sleep, they didn't delay here they also left. And they didn't wake me up to close the door. They say they didn't think I was asleep. When they left ... they sleep down there (points to an opposite hut) and the other boy usually goes up there. So he lied to my brothers that he had left also and he came back later because he knew the door was not closed. 
So when I woke up, I found when ... hmmmm ... when he was on me ... and I was naked. When I tried to call my grandmother, it was when he closed my mouth so that my voice couldn't come out. So I kept quiet and that's when he left quietly. So even me I was filled with fear. I just kept quiet till morning. Even in the morning, I didn't tell my grandmother. I just went to the teacher and reported and that's when we went to the hospital.

At the health facility, they took her medical history after which she was tested for HIV and later given emergency contraceptives and antiretroviral drug. A physical examination and a forensic examination were then performed. The first author asked if permission was sought by the examining officer for any activity. She replied:

Us (her and the female teacher) when we went and explained to him, he just took blood and gave me the medicine (Why did he take blood?) It was for AIDS .... (Do you remember what he said the medicine was for?) The one for pregnancy and AIDS. (Did he say anything else?) No. He just gave medicine and looked at my body. (Did he tell you why he was looking at your body?) No .... (How did you feel when he was looking at your body?) (Laughs) I felt fear.

After the examination, they were told to go to the police station. The first author inquired Christine if she knew why they went to the police. She responded:

I don't know why we went. We went even me I wrote (recorded a statement about the incident). We just went with the teacher.

The first author then asked her if any arrests had been made. She said:

He has not been even arrested. I always see him here. (How does that make you feel?) I don't feel well (meaning she was not happy).

Upon conclusion of the interview, the first author obtained verbal consent from her guardian to speak to police officers in charge of case and review her medical records.

\section{Review of Christine's health records Medical files}

Christine had been seen on September 25, 2013 (not the real date), with follow-up visits on day 14 and day 28. Despite the fact that she was on antiretroviral drugs, no liver function and hemoglobin tests were done during the visits. Additionally, she was not tested for sexually transmitted illnesses and pregnancy. The research team made a follow-up with the examining clinician on reasons for failure to carry out recommended tests. He stated that he did not remember the exact reasons but cited possible reasons to be patients coming out of the normal working hours and lack of testing reagents and kits.

\section{Medicolegal records}

Both P3 and PRC1 forms had been filled. On the PRC1 form under section titled chief complaint, the examining medical officer had noted defilement with no symptoms. However, in the $\mathrm{P} 3$ form where a description of details on the physical state of the genitalia was required, the examining medical officer had noted normal female genitalia, inflamed labia minora noted with whitish substance on the labia minora. The hymen is absent. Further inquiry on the same form for the presence of discharge, blood or venereal infection, from genitalia or on body externally, the examining medical officer had noted a dry whitish substance. Semen on the labia majora noted. Despite the observation of whitish substance, samples had not been collected for investigation. When the first author asked why the samples were not collected, she was informed that the health facility lacked equipment for collecting dry samples.

\section{Follow-up with the police}

The police officer in charge of the case took the research team through the case. They were informed that the perpetrator had not been arrested due to lack of sufficient evidence for prosecution. The police officer doubted Christine's claim of the sexual abuse. According to him, the rape had occurred with the grandmother in a nearby room. Despite that, her grandmother did not hear any screams and refused to record a statement to the police. He also stated that Christine had claimed to have been strangled, but there were no strangulation marks. He proceeded to show the researchers a section on the PRC1 form that indicated chief complaint defilement with no symptoms. To him that was an indication that no "defilement" had taken place.

The police officer then concluded that the whole incident was a lie. The first author pointed out to him that that would be the magistrate's decision to make. He stated that he resented looking clueless during court sessions and was unwilling to present a case that lacked sufficient evidence. $\mathrm{He}$ proceeded to narrate his losses at the law courts. According to him, many guardians opted out when they received compensation from "Kangaroo courts" (informal justice systems) for child sexual abuse. In turn, they would hide their children from the criminal justice system when time came for such cases to be heard in court. In court, some guardians advised their children to lie about their ages. Later on, the same 
survivors would marry their alleged perpetrators. As a result, he was always hesitant when it came to pursuing rape cases involving minors.

\section{Discussion}

This is the first study to detail survivors' experiences when seeking postrape care services, at both the health facility and criminal justice system level in Kenya. From the illustrative cases, it is clear that the minors' right to the quality health care and justice were violated.

Delays in receiving postrape care services experienced by Edna at the health facility could have been as a result of health providers' attitude toward sexual violence, understaffing, lack of training, and inaccessibility of services. Judging from the long wait to which Edna was subjected to at the health facility, it can be said that sexual violence was not considered an emergency. If it was, the medical officer would have come sooner. A study conducted in South Africa on the quality of health services for rape survivors showed that health providers did not consider sexual assault as a serious medical condition. ${ }^{27}$ If the health facility had been well staffed, then Edna could have been seen by another medical officer. This finding aligns with findings from a Kenyan study that reported a shortage of medical doctors to conduct forensic examinations. ${ }^{28}$ Although the nurse was available at the time Edna arrived at the health facility, she only performed the HIV test. Had she been trained to perform forensic examinations, Edna's waiting period could have been shortened. A Kenyan study on challenges experienced by service providers in delivery of medicolegal services to survivors noted that despite national guidelines allowing nurses to perform forensic examinations, most of them reported having limited skills. ${ }^{28}$ Multiple returns to the health facility due to unavailability of particular services out of the working hours left Edna with unmet health needs. There is a need for more staffing and proper planning in health facilities to ensure that postrape care services are available 24/7.

By summoning "the girl who had been raped", Edna's examining medical officer's demonstrated a lack of empathy, sensitivity, and consideration for ethics as well as privacy. Studies have shown that young people face multiple barriers to seeking health services, including lack of autonomy, confidentiality, and information on available services. ${ }^{29,30}$ In both cases, consent was not obtained from minors, and all aspects of the consultation were not explained. These actions violated the minors' rights to quality health care, autonomy, bodily integrity, and dignity. Since sexual assault causes survivors to experience a sense of powerlessness, ${ }^{10}$ it is important to seek informed assent so as to minimize feelings of anxiety and powerlessness and perhaps help replace such emotions with a sense of choice and control. ${ }^{31,32}$

The medical officer's unpreparedness for the forensic examination could be attributed to the lack of protocols as observed in a study conducted in Northern Uganda where only one of the eight health facilities visited used a protocol for treating survivors of sexual violence. ${ }^{33}$ Protocols should recommend provision of rape kits that contain information package on forensic examination and the requisite medical supplies and equipment, ensuring that the uncomfortable examinations are done within the shortest time possible. The information package with instructions on how to conduct forensic examinations is resourceful for inexperienced health providers. Since forensic evidence weighs heavily in judicial proceedings of sexual assault cases, the collection of evidence must strictly adhere to national protocols. ${ }^{34,35}$ Therefore, it is imperative that health facilities formulate local protocols that align with the national protocols to ensure quality health care through proper assessment of survivors and collection of evidence.

Edna's examining medical officer's inability to collect samples could be attributed to a lack of training and inexperience. Subjection of minors to unnecessary speculum examinations is discouraged as forensic examination is sometimes viewed by survivors as a second rape. ${ }^{36}$ When performed without consent, they violate an individual's right to autonomy, privacy, and bodily integrity. Absence of medical supplies and equipment as highlighted by lack of lighting sources, gloves, and emergency contraceptives hampers provision of quality health care. This violates the minors' right to quality health care that encompasses access to essential medicines and availability of health care facilities. ${ }^{12}$ Our findings align with Patel et al's ${ }^{37}$ study that reported health facilities in the USA lacked resources to provide comprehensive postsexual assault services. Lack of medical supplies for the otherwise free services places the cost burden on survivors who are already financially strained. Health policy makers and implementers need to ensure that comprehensive postrape care training is offered to medical students and health providers to ensure quality health care provision, adherence to ethics, and respect of patients' rights. Additionally, efforts should be made by health policy makers and implementers to ensure that health facilities are well equipped and stocked to meet health needs of survivors seeking postrape care services.

Both cases experienced difficulties in their interaction with the criminal justice system. Edna was subjected to 
recording of numerous statements and delays at the police station to the extent that it affected her access to health care. Christine's case was dismissed as a lie with no investigations conducted by the police. Reports show that investigations of sexual and gender-based violence cases in Kenya are conducted poorly by the police and often result in very few convictions. ${ }^{17,38}$ Dismissal of Christine's case was based on the fact that no one heard her scream. A Kenyan study on rape myth attitudes found that in order for a stereotypical victim of sexual abuse to be believed, she should have been heard screaming or aggressively fought the perpetrator. ${ }^{39}$ Studies show that most agents of the criminal justice system have poor attitudes toward female survivors of sexual violence with a tendency of being insensitive to their needs, blaming them for the abuse, and having unjustified doubts in regard to the filed charges. ${ }^{40-44}$ In addition, the police officer did not take time to go through the entire medical report before concluding that there was no rape. Disbelief by figures of authority during disclosure contributes to underreporting. ${ }^{45}$ The delays at the criminal justice system could have contributed to the alleged engagement of Edna's guardians' in negotiations with the perpetrator. The police officer stated that many guardians opted out of the criminal justice systems when they received compensation from the traditional justice system. This finding aligns with a Kenyan study that showed a preference for informal justice systems by guardians of survivors of sexual abuse due to monetary gains thus undermining the legislative enactments and criminal sanctions. ${ }^{24}$ To encourage reporting and support of survivors of sexual violence, police officers should be trained on sexual and gender-based violence, its manifestations, and effect of negative attitudes on survivors.

As illustrated in the cases of Edna and Christine and previously discussed, the guardians, the police officer, and the medical officer did not offer sufficient care and support to the minors. Both minors were unaccompanied by their guardians to the health facility. Although this phenomenon could be explained by lack of protocols, training, supervision, medical supplies, and equipment, it could also be argued that the insufficient support and care offered was influenced by cultural perceptions of rape. Research shows that culture is a strong determinant of how society perceives and responds to reports of sexual violence. ${ }^{46}$ According to a Kenyan study on engendered development in rural Kenya, women reside in a cultural setting characterized by patriarchy and inequity that tolerates sexual and gender-based violence. ${ }^{47}$ Consequently, laws against sexual and gender-based violence are rarely enforced due to societal attitudes that shift blame to the survivors and view actions of the perpetrator as normal since sexual desire and arousal in men is seen as uncontrollable. ${ }^{48}$ Communities need to be made more aware of not only the consequences of sexual violence and the rights of minors and women but also sociocultural traditions and attitudes that tend to perpetuate or contribute to their vulnerability in order to promote behavioral change.

There is a need for a review of the national guidelines on the management of sexual violence. The guidelines need to reemphasize informed consent and assent, especially in cases where the alleged perpetrator is the guardian. The guidelines also need to expound on privacy and confidentiality, in terms of what is meant by each term and how each concept can be maintained in the delivery of postrape care. Since the guidelines are not fully operationalized or widely accessible, efforts should be made by the Kenyan Government to ensure that the guidelines are available in every health facility and that all appropriate health providers are aware of them and what to do. Additionally, health administrators should be held accountable for the quality of postsexual assault services offered to ensure good governance.

Limitations inherent to the study merit discussion. First, the study sample was quite small. However, based on the fact that sexual abuse is sensitive and less research has been conducted on processes of postrape care, the findings are extremely relevant. Although the findings are from one health facility, they are representative as the facility was a referral center for other health facilities within Homa Bay County and a teaching center for prospective health providers. It could have been useful to know about Edna's whereabouts and her predicament. The research team was unable to trace her but felt that her disappearance highlights the complexity and gravity of child sexual abuse and its potential consequences. The research team also did not probe guardians on reasons for not accompanying their dependants to the health facility despite the relevance of such information. Due to the sensitivity of the theme and the effect of sexual abuse on the caregivers, we thought that the questions would be considered adversarial.

\section{Implications for research}

More research needs to be done on processes of postrape care within health facilities and services offered by the criminal justice system to minors who have experienced sexual abuse to assess their effectiveness and efficiency. There is also a need to understand why caregivers of children who have experienced prefer informal justice systems to criminal justice systems. Reasons behind their preference will help 
in improving the criminal justice system so as to meet the needs of survivors of sexual violence.

\section{Conclusion}

This study highlights violations of rights of minors seeking postrape care services at the health and legal systems. The study shows a lack of protocols, medical supplies, and equipment within the health facilities, conveying a low priority to such offenses and vulnerable group. Protocols should be amended to include sexual and reproductive health rights and made available in health facilities. The Kenya Sexual Offences Act 2006 needs to be amended to include reparation for survivors of sexual abuse to provide ways of alleviating survivors' suffering. Minors who had already suffered abuse were subjected to more abuse by the health providers and legal officers due to lack of training and negative attitudes. Both health providers and legal officers need training on sexual and gender-based violence and its consequence in order to promote compassionate, ethical, and nonjudgmental postrape care services. In addition, the community needs to be sensitized on child sexual abuse, its consequences, and support for minors who have been sexually abused. The prevention of child sexual abuse must be intimately linked to efforts to transform the status of minors, especially girls in the community.

\section{Acknowledgment}

The research was funded by Ivar Helle's Foundation.

\section{Disclosure}

The authors report no conflicts of interest in this work.

\section{References}

1. Stoltenborgh M, Van Ijzendoorn MH, Euser EM, BakermansKranenburg MJ. A global perspective on child sexual abuse: meta-analysis of prevalence around the world. Child Maltreat. 2011;16(2):79-101.

2. Pedera N, Guilera G, Forns M, Gomez-Benito J. The prevalence of child sexual abuse in community and student samples: a meta analysis. Clin Rev Psychol. 2009;123(1):328-338.

3. Daru PH, Osagie EO, Pam IC, Mutihir JT, Silas OA, Ekwempu CC. Analysis of cases of rape as seen at the Jos University Teaching Hospital, Jos, North Central Nigeria. Niger J Clin Pract. 2011;14(1):47-51.

4. Brown DW, Riley L, Butchart A, Meddings DR, Kann L, Harvey AP. Exposure to physical and sexual violence and adverse health behaviours in African children: results from the global school-based student health survey. Bull World Health Organ. 2009;87(6):447-455.

5. UNICEF. Violence against Children in Kenya: Findings from a 2010 National Survey. Nairobi: UNICEF, CDC \& KNBS; 2012.

6. Reza A, Breiding MJ, Gulaid J, et al. Sexual violence and its health consequences for female children in Swaziland: a cluster survey study. Lancet. 2009;373(9679):1966-1972.

7. Dube SR, Anda RF, Whitfield CL, et al. Long-term consequences of childhood sexual abuse by gender of victim. Am J Prev Med. 2005;28(5): 430-438.
8. Danielson CK, Macdonald A, Amstadter AB, et al. Risky behaviors and depression in conjunction with - or in the absence of - lifetime history of PTSD among sexually abused adolescents. Child Maltreat. 2010;15(1): 101-107.

9. Classen CC, Palesh OG, Aggarwal R. Sexual revictimization: a review of the empirical literature. Trauma Violence Abuse. 2005;6(2):103-129.

10. Jina R, Jewkes R, Munjanja SP, et al; FIGO Working Group. Report of the FIGO Working Group on Sexual Violence/HIV: guidelines for the management of female survivors of sexual assault. Int $J$ Gynaecol Obstet. 2010;109(2):85-92.

11. Cybulska B. Immediate medical care after sexual assault. Best Pract Res Clin Obstet Gynaecol. 2013;27(1):141-149.

12. WHO. Sexual Health, Human Rights and the Law. Geneva: World Health Organizations; 2015.

13. WHO. Defining Sexual Health: Report of a Technical Consultation on Sexual Health, 28-31 January 2002. Geneva: World Health Organization; 2006.

14. UNHRC. Article 24, Convention on the Rights of Children. Geneva: Council UNHRC; 1989

15. UNHRC. Article 39, Convention on Rights of the Child. Geneva: Council UNHRC; 1989

16. Ringheim K. Ethical and human rights perspectives on providers' obligation to ensure adolescents' rights to privacy. Stud Fam Plann. 2007; 38(4):245-252.

17. KNCHR. Kenya 2014 Human Rights Report. Nairobi: Kenya National Human Rights Commission; 2014.

18. Ministry of Medical Services and Ministry of Public Health \& Sanitation. National Guidelines on Management of Sexual Violence in Kenya. 2nd ed. Nairobi: Ministry of Medical Services \& Ministry of Public Health \& Sanitation; 2009.

19. Reddy DM, Fleming R, Swain C. Effect of mandatory parental notification on adolescent girls' use of sexual health care services. JAMA. 2002; 288(6):710-714.

20. Schuster MA, Bell RM, Petersen LP, Kanouse DE. Communication between adolescents and physicians about sexual behavior and risk prevention. Arch Pediatr Adolesc Med. 1996;150(9):906-913.

21. Klein JD, Wilson KM, McNulty M, Kapphahn C, Collins KS. Access to medical care for adolescents: results from the 1997 Commonwealth Fund Survey of the Health of Adolescent Girls. J Adolesc Health. 1999; 25(2):120-130

22. UNHRC. Article 34, Convention on Rights of the Child. Geneva: Council UNHRC; 1989

23. Government of Kenya. Sexual Offences CAP 62A, Act of 2006. GOK. Kenya: Laws of Kenya; 2006.

24. Kilonzo N, Ndung'u N, Nthamburi N, et al. Sexual violence legislation in sub-Saharan Africa: the need for strengthened medico-legal linkages. Reprod Health Matters. 2009;17(34):10-19.

25. Chandiramani R, Misra G. Sexuality, Gender and Rights: Exploring Theory and Practice in Southeast Asia. New Delhi: SAGE; 2005.

26. Cornwall A, Wellborne A. Realizing Rights: Transforming Approaches to Sexual and Reproductive Well being. London: Zed Books; 2002.

27. Christofides NJ, Jewkes RK, Webster N, Penn-Kekana L, Abrahams N, Martin LJ. "Other patients are really in need of medical attention" - the quality of health services for rape survivors in South Africa. Bull World Health Organ. 2005;83(7):495-502.

28. Ajema C, Mukoma W, Kilonzo N, Bwire B, Otwombe K. Challenges experienced by service providers in the delivery of medico-legal services to survivors of sexual violence in Kenya. J Forensic Leg Med. 2011; 18(4):162-166.

29. Booth ML, Bernard D, Quine S, et al. Access to health care among Australian adolescents young people's perspectives and their sociodemographic distribution. J Adolesc Health. 2004;34(1):97-103.

30. Akinfaderin-Agarau F, Chirtau M, Ekponimo S, Power S. Opportunities and limitations for using new media and mobile phones to expand access to sexual and reproductive health information and services for adolescent girls and young women in six Nigerian states. Afr J Reprod Health. 2012;16(2):219-230. 
31. Greeson MR, Campbell R. Sexual assault response teams (SARTs): an empirical review of their effectiveness and challenges to successful implementation. Trauma Violence Abuse. 2013;14(2):83-95.

32. McGregor MJ, Du Mont J, White D, Coombes ME. Examination for sexual assault: evaluating the literature for indicators of women-centered care. Health Care Women Int. 2009;30(1-2):22-40.

33. Henttonen M, Watts C, Roberts B, Kaducu F, Borchert M. Health services for survivors of gender-based violence in northern Uganda: a qualitative study. Reprod Health Matters. 2008;16(31):122-131.

34. Krolikowski AM, Koyfmann A. Emergency centre care for sexual assault victims. Af J Emerg Med. 2012;2(1):24-30.

35. Welch J, Mason F. Rape and sexual assault. BMJ. 2007;334(7604): 1154-1158.

36. Ministry of Medical Services \& Ministry of Public Health \& Sanitation Kenya Health Policy. Nairobi: Ministry of Medical Services \& Ministry of Public Health and Sanitation; 2012.

37. Patel A, Roston A, Tilmon S, et al. Assessing the extent of provision of comprehensive medical care management for female sexual assault patients in US hospital emergency departments. Int J Gynaecol Obstet. 2013;123(1):24-28.

38. ACORD. Pursuing Justice for Sexual and Gender Based Violence in Kenya: Options for Protecting and Compensating Survivors of Sexual and Gender Based Violence. Nairobi: Agency for Cooperation and Research in Development; 2010.
39. Tavrow P, Withers M, Obbuyi A, Omollo V, Wu E. Rape myth attitudes in rural Kenya: toward the development of a culturally relevant attitude scale and "blame index". J Interpers Violence. 2013;28(10): 2156-2178.

40. Belknap J. The Invisible Woman: Gender, Crime \& Justice. Belmont, CA: Wadsworth; 2001.

41. Koss MP. Blame, shame \& community: justice responses to violence against women. Am Psychol. 2000;55(11):1332-1343.

42. Stanko EA. Intimate Intrusions: Women's Experiences of Male Violence. London: Routledge \& Kegan Paul; 1985.

43. Searles P, Berger RJ. Rape \& Society: Readings on the Problem of Sexual Assault. Boulder, CO: Westview Press; 1995.

44. Gregory J, Lees S. Policing Sexual Assault. London: Routledge; 1999.

45. Pinheiro. World Report on Violence against Children. Geneva: United Nations; 2006

46. Kalra G, Bhugra D. Sexual violence against women: understanding crosscultural intersections. Indian J Psychiatry. 2013;55(3):244-249.

47. Maseno L, Kilonzo S. Engendering development: demystifying patriachy and its effects on women in Kenya. Int J Sociol Anthropol. 2011;3(2): 45-55.

48. Erulkar AS. The experience of sexual coercion among young people in Kenya. Int Fam Plan Perspect. 2004;30(4):182-189.
International Journal of Women's Health

\section{Publish your work in this journal}

The International Journal of Women's Health is an international, peerreviewed open-access journal publishing original research, reports, editorials, reviews and commentaries on all aspects of women's healthcare including gynecology, obstetrics, and breast cancer. The manuscript management system is completely online and includes

\section{Dovepress}

a very quick and fair peer-review system, which is all easy to use. Visit http://www.dovepress.com/testimonials.php to read real quotes from published authors. 